\title{
A BLOGOSFERA MATERNAÉ BRANCA: TRABALHO, FEMINISMOS, RAÇA E CLASSE NA BLOGOSFERA MATERNA BRASLLEIRA
}

\author{
THE MATERNAL BLOGOSPHERE IS WHITE: WORK, FEMINISMS, RACE AND CLASS IN THE BRAZILIAN \\ MATERNAL BLOGOSPHERE
}

\section{RESUMO}

Este artigo versa sobre a não neutralidade racial e de classe dos blogs maternos brasileiros na última década. Apresento a discussão a partir da identificação feita por mulheres negras da ausência na blogosfera materna de temas pertinentes às suas experiências de maternagem e às questões que as afligem. Este diagnóstico, que as motiva a criar blogs maternos e grupos de mulheres específicos para o debate da maternidade negra, visibiliza como a blogosfera materna brasileira, que não reivindica recorte racial e de classe, é marcada pela branquitude. Reforço o argumento através da apresentação de enunciados proferidos em blogs escritos por mulheres mães brancas acerca dos feminismos. O debate, que se centra no trabalho remunerado fora do lar geralmente visto como símbolo de libertação ou de opressão feminina, além de manter a mulher como principal cuidadora das crianças, evidencia o perfil das mulheres que participam da construção deste discurso e as teorias feministas que o embasam. Nesta análise, dialogo com a autora afro-americana bell hooks, a qual evidencia como certos discursos maternalistas refletem o viés de classe e raça das participantes e como questões relativas ao cotidiano e à prática de ser mãe das mulheres negras encontram-se ausentes de modelos de maternidade romantizados que invocam a maternidade como um dado da natureza feminina e, consequentemente, universal.

Palavras-chave: Maternidade. Maternagem. Blog materno. Branquitude. Feminismo.

\begin{abstract}
This article discusses the racial and class non-neutrality of Brazilian maternal blogs in the last decade. I present the debate based on the identification made by black women of the absence in the maternal blogosphere of themes relevant to their mothering experiences and the issues that afflict them. This diagnosis, which motivates them to create maternal blogs and specific women's groups for the debate on black motherhood, visibilizes how the Brazilian maternal blogosphere, which does not claim racial or class focus, is marked by whiteness. I reinforce the argument by demonstrating statements present in blogs written by white mother women about feminisms. The debate, which is focused on paid work outside the home, usually seen as a symbol of female liberation or oppression, in addition to keeping women as the main caregivers of children, highlights the profile of women who participate in
\end{abstract}

Elaine Muniz Pires

Faculdade de Educação da Universidade de São Paulo (FE-USP). E-mail: elainempires@hotmail.com 
the construction of this discourse and the feminist theories that support it. In this analysis, I dialogue with the African-American author bell hooks, who shows how certain maternalist discourses reflect the participants class and race biases, as well as how issues related to the daily life and practice of being a black mother are absent from romanticized maternity models that invoke motherhood as a given fact of the female and, thus, universal nature.

Keywords: Maternity. Mothering. Maternal blog. Whiteness. Feminism.

\section{Introdução}

No início do século XXI, verificou-se um crescimento de blogs maternos em defesa de práticas naturais de parturição e de cuidados infantis no Brasil. Nomeando-se frequentemente mães ativas, por vezes como mamíferas, mulheres mães passaram a usar este recurso online para dividir angústias e experiências de maternagem, para apoiarem-se mutuamente, para compartilhar informações científicas de diferentes vertentes sobre parturição e cuidado infantil e também para fortalecer o ativismo por causas maternas e infantis. $\mathrm{O}$ discurso e a prática construídos neste ambiente on-line enunciam a possibilidade de escolha da mulher de ser mãe, de como ser mãe e de como maternar e reivindicam posturas e princípios feministas.

O conjunto de blogs que aborda a questão da maternidade e maternagem, referenciado como blogosfera materna, é adjetivado apenas no que tange ao tema a que se dedicam. Não há uma delimitação anunciada de quais mães podem dele participar ou se há um recorte na temática a fim de concentrar-se em questões relativas a uma classe, a uma raça ou a uma região do país. Sob o manto da neutralidade, estes blogs são, a princípio, abertos à participação de qualquer mulher, assim como a rigor qualquer mãe pode aderir a práticas de maternagem que não as mais convencionais. O público atingido e construtor deste discurso, no entanto, é majoritariamente constituído por mulheres brancas, intelectualizadas, de classes médias ou altas. Raras são as blogueiras ou comentaristas negras. Raras são as fotos de perfil e as imagens que ilustram os relatos de parto e de amamentação de mulheres não brancas. A predominância deste público pode ser verificada também nas questões debatidas, centradas em experiências de maternagem, correspondentes aos lugares sociais que ocupam e que pouco incluem outras formas de ser mãe e de maternar.

Evidentemente este quadro se deve aos privilégios da branquitude tanto pelo acesso facilitado à internet de qualidade e à informação, quanto pela disponibilidade de tempo para refletir acerca da criação dos filhos, para debater e escrever na blogosfera. Afinal, possuir uma rede de apoio (como familiares que ajudam no cuidado), contratar babás ou trabalhadoras domésticas (muitas delas negras) ou deixar os filhos por longos períodos em instituições escolares, libera 
as mães brancas de parte do trabalho doméstico e do cuidado infantil. Renda familiar mais alta, trabalhar em locais próximos à moradia, número menor de filhos, letramento digital, conhecimento e qualificação para buscar seus direitos, também são condições que compõem este privilégio.

Neste artigo, proponho a reflexão sobre como o que se passou a chamar de blogosfera materna no Brasil, diz respeito a discursos proferidos e construídos por um grupo seleto de mulheres brancas em blogs voltados à maternidade, ainda que em seus debates não exista o reconhecimento deste marcador social. Apresento a discussão a partir da criação de blogs específicos para discussão da maternidade e maternagens negras, assim como da análise de enunciados proferidos em blogs maternos escritos por mulheres brancas acerca do feminismo. Nesta análise, dialogo com a autora afro-americana bell hooks, a qual evidencia como certos discursos maternalistas refletem o viés de classe e raça das participantes e como questões relativas ao cotidiano e à prática de ser mãe das mulheres negras encontram-se ausentes de modelos de maternidade romantizados que invocam a maternidade como um dado da natureza feminina e, consequentemente, universal. Argumento que esta formação discursiva é embasada em teorias feministas erigidas por mulheres brancas e que há um predomínio de visões feministas brancas no debate contemporâneo maternalista no Brasil.

\section{A blogosfera materna negra}

Grupos de mães, maternidade, maternagem e afins são sempre ocupados por mulheres brancas. E muitas das informações compartilhadas são para crianças Brancas (sic). É como se as pautas, vivências e experiências de mulheres negras e crianças negras não existisse (sic) (ASSUNÇÃO, 2017, online).

Criados em 1997, os blogs, que funcionam como sites pessoais, popularizaramse na primeira década dos anos 2000, dada a facilidade para edição, atualização e manutenção de páginas on-line. Neste período, surgiram os primeiros blogs dedicados a temas ligados à maternidade no Brasil, como o Mothern ${ }^{1}$ (2002). Neles, as mulheres narram sua vida como mães à medida que criam seus filhos, relatam seus partos, relatam suas vivências, dividem angústias, dúvidas e felicidades relativas à maternidade e à maternagem, divulgam informações científicas quanto às formas de cuidado. As mulheres que o escrevem e o acessam o fazem em busca de informações, de conselhos, de apoio, de conexão com outras mães.

1 O sucesso do blog levou ao lançamento do livro Mothern- Manual Mãe Moderna (Editora Matrix), escrito pelas criadoras do blog Laura Guimarães e Juliana Sampaio em 2005 e inspirou a série de televisão Mothern, que estreou no canal GNT em 2006. 
O primeiro blog que se propõe a discutir as especificidades da questão racial na maternidade que temos notícia foi o Uma Mãe feminista criado em 2013, mais de uma década após o surgimento do Mothern. A autora, Karoline Miranda, historiadora e jornalista, refere que começou a escrever quando, durante a gravidez, descobriu que a vida de grávida e de mãe não é tão bonita como mostrada nos filmes e nas novelas, sobretudo quando se trata de uma mulher negra. Em seu blog, voltado à autorreflexão e ao provimento de ajuda a outras mulheres em situação análoga, o recorte racial está presente e é considerado essencial e necessário por ela. Isto por que

Eu consumi muito conteúdo branco (e ainda caio nesse gatilho) e quando tento aplicar a mim, aquilo não se encaixa e eu me sentia/sinto horrível. Negros são uma minoria social, mas não populacional (pelo contrário). Sempre somos vistos como faxineiras, domésticas, babás, porteiros, seguranças, bandidos, a televisão reforçou isso por décadas, a internet reforça isso muitas vezes. Esse espaço também é nosso, e quanto mais eu vejo que a gente ocupa esse espaço, mais sinto que ajudo a construir um mundo melhor para o meu filho (VIANA, 2019, online).

O diagnóstico de Karoline Miranda de que a blogosfera materna não trata de temáticas caras às mulheres negras é compartilhado por outras blogueiras negras, como por Priscila Silva, criadora do blog do Instagram Mãe nada convencional,

Um dia a ficha caiu: a blogosfera materna tem raça e é monocromática branca!! E tudo aquilo que eu sentia era uma completa falta de representatividade. Por muito tempo procurei e não encontrei nada sobre o cabelo crespo infantil, sobre autoestima da criança negra, sobre os cuidados com a pele da criança negra ... (SILVA, 2017, online).

Luciana Bento, historiadora e criadora do blog A Mãe Preta (2014), também refere à dificuldade em debater preocupações de mães negras em blogs maternos como motivador para criação de seu blog. A historiadora relata ter cansado de procurar na internet um lugar para compartilhar experiências como mãe de duas meninas negras e de tentar discutir em vão sobre racismo na maternidade. Ela aponta que se sentia deslocada nos fóruns de maternidade quando queria falar sobre racismo, sobre os preconceitos vividos ou sobre como a violência obstétrica atinge mais as mulheres negras. Por sentir falta de espaços que tratassem de questões específicas da realidade de mães e crianças como ela e suas filhas, criou seu blog buscando propiciar o diálogo entre estas mulheres. Nele, a autora escreve sobre como lida com o preconceito, como trabalha a autoestima das filhas, como criar estratégias para enfrentar o racismo na infância (JORNAL ROSA CHOQUE, 2018). 
Outra iniciativa em busca de oportunizar o diálogo entre mães negras e fortalecê-las foi a criação em 2017 do blog Nana Maternidade Negra: visibilidade, cor e ancestralidade a maternidade ${ }^{2}$. O projeto de blogagem coletiva, voltado ao universo da maternidade negra, busca atingir o máximo de mulheres possível e construir uma rede de apoio entre mães negras, a partir do compartilhamento de suas vivências e realidades específicas.

O projeto NANA - Maternidade Preta tem o objetivo de dar voz a esta pauta necessária para nós, mulheres negras e mães. Vamos falar do que nos une, nos enriquece, nos enlouquece, nos entristece, nos aflige, nos faz sorrir e ao mesmo tempo nos faz chorar. Com ajuda de profissionais negros, buscaremos tratar de assuntos que envolvem o cotidiano individual ou generalizado, pois o nosso maior objetivo é que as mães pretas possam se identificar com nossas pesquisas, e para isto, daremos voz às mães pretas do corre, procurando manter o eixo entre a ancestralidade e a atualidade (CAVALLIERI, 2017, online).

Mayara Assunção, uma das idealizadoras do Nana Maternidade Negra, também evidencia a ausência de debates na blogosfera materna que se refiram às realidades de outras mães. Em um de seus textos, a blogueira discute o silêncio da blogosfera materna quanto ao desafio de criar crianças negras em uma sociedade estruturalmente racista como a nossa. Para ela, isto ocorre porque as pessoas brancas não querem abrir mão de seus privilégios. As lutas das maternalistas feministas que falam de bem-estar e melhorias no universo infantil "não vão além de nenhuma melhoria que esteja fora do seu círculo e da sua proteção" (ASSUNÇÃO, 2017, online), afirma a autora. Para Mayara, apesar da defesa de uma maternagem cada vez mais humana, a questão racial parece ter ficado de fora. Ela se pergunta se exercer uma maternidade ativa e responsável, como propagada nos blogs, "é mesmo fechar os olhos para as falas de Mães Negras?” (ASSUNÇÃO, 2017, online).

Neste sentido, Carla Cavallieri, que também escreve para este projeto de blogagem coletiva, professora formada em história e pesquisadora de Mitologia Iorubá, afirma que muitas mães brancas questionam e ironizam a demanda por um espaço exclusivo de debate da maternidade negra (SILVA, 2018). Em um de seus textos publicado no blog, Carla desabafa:

Mas, pera, não dá, por mais que vocês não vejam, eu vou falar, preciso falar... Falar que nós não somos vistas, que nossas dores não importam, ou que nossa condição de maternidade é a pior. (...) A verdade é que vocês nunca irão enxergar a nossa realidade, porque não é a de vocês, ou mesmo, porque não se importam. (...) A verdade é que a nossa demanda precisa urgentemente estar em

2 O Nana Maternidade Negra foi criado por Carla Cavallieri, Clélia Rosa, Dani Barbosa, Mayara Assunção e Cíntia Aleixo (BLOGUEIRAS NEGRAS, 2017). 
pauta, e não vem dizer que mulher negra éa mesma coisa que mãe, que não é, há uma hora em que os caminhos se dividem, e nós precisamos ser acolhidas, respeitadas, humanizar-nos é preciso irmãs (sic). (...) Nossas demandas são diferentes, exigem respeito, voz e cuidado... Mas principalmente união (sic) (CAVALLIERI, 2018, online).

Em busca de respeito, em busca de visibilidade e de reconhecimento de suas particularidades, estes blogs criados por mulheres negras têm em comum a identificação da falta de reconhecimento da realidade e demanda de questões que as afligem nos demais blogs de maternidade que não reivindicam um recorte racial e ou econômico. Para além dos debates que são discutidos em outros espaços como as escolhas possíveis de parto ou locais para realizá-los, a alimentação do bebê, amamentação, cama compartilhada, entre outros, há a necessidade de debater questões relacionadas ao cotidiano das mães e crianças negras, como o preconceito na escola, como fortalecer a autoestima das crianças, como lidar com a violência policial e com a violência obstétrica direcionadas à população negra. Para este público algumas questões debatidas nos blogs brancos são menos urgentes frente a outras demandas. Debater quanto a mulher que opta em não trabalhar após o nascimento dos bebês é ou não feminista, é ou não emancipada, é uma das preocupações nas quais pouco se debruçam as mães negras, tendo em vista que a maioria destas mulheres sempre trabalhou e não tem a expectativa de se libertar da dominação masculina através da entrada no mercado de trabalho.

A violência obstétrica, assunto muito debatido na blogosfera branca, é discutido entre as blogueiras negras em sua especificidade, no reconhecimento de que atinge mais as parturientes atendidas pelo SUS em sua maioria mulheres negras 3 . Karoline Miranda (2016, on-line), por exemplo, em seu relato de parto, conta que considerou "idiota” a prioridade de sua mãe antes de levá-la ao hospital para o parto: lixar seus pés e limpar possíveis "cascões" de seu pescoço: "ela não queria que enfermeira nenhuma me achasse 'favelada', porque sabia que se isso acontecesse, eu seria maltratada”. Em sua experiência no hospital público, compreendeu o temor de sua mãe ao testemunhar o desejo de uma médica de que uma adolescente negra sofresse na sala de pré-parto lotada porque, na avaliação da profissional, a jovem estava drogada e fedia, e os risos dos profissionais de saúde aos ouvir os gemidos de uma senhora angolana.

\footnotetext{
3 A mortalidade materna é duas vezes e meia maior em mulheres pretas do que em brancas no Brasil. Em comparação às brancas, as puérperas negras possuíam maior risco de receberem um pré-natal inadequado e de terem que peregrinar por hospitais para a realização do parto, menor índice de acompanhante durante o parto, além de receberem menos anestesia local para episiotomia (LEAL, 2017). Ainda que a violência obstétrica também faça parte da realidade dos hospitais privados, no SUS ela é usual, o que leva as mulheres pobres, negras, adolescentes, presidiárias a sofrerem mais violência dos profissionais de saúde, que sentem autorizados a puni-las por seus erros, por suas escolhas, por machismo, julgamento da vida sexual, idade, ou por preconceitos morais, sociais e raciais (AGUIAR, 2016).
} 
Outro tema que passa longe dos blogs maternos brancos é a necessidade de estimular a autoestima das crianças negras. Luciana Bento, com este objetivo, criou a livraria itinerante especializada em literatura negra "Iná Livros", o projeto “10o livros infantis com meninas negras" em 2016 e passou a ministrar palestras e oficinas de literatura em escolas. Luciana também participa de encontros presenciais com mães negras do Iyá Maternância ${ }^{4}$, que tem como finalidade criar redes de apoio por mães pretas e para mães pretas, compartilhar os sentimentos e situações por que passam estas mulheres e combater opressões racistas e machistas que as atingem.

Luciana Bento, Karoline Miranda, as idealizadoras do Naná Maternidade Negra e aquelas que integram o Iyá Maternância, evidenciam como os blogs maternos, como as discussões na internet sobre maternidade e maternagem são majoritariamente ocupados e feitos por e para pessoas brancas. Elas sinalizam para a necessidade de ampliação dos debates dos temas tratados na blogosfera a fim de abranger problemas mais amplos e estruturais como o racismo e as condições socioeconômicas de mães e crianças negras. Ao procurar dar visibilidade e criar um espaço para o debate de questões que afligem a maternidade negra, elas também acabam por visibilizar que não há neutralidade na blogosfera, que o que se supõe neutro ou universal, é marcado pela branquitude e reflete a posição de poder ocupada por pessoas brancas na sociedade.

\section{A blogosfera materna branca, feminismos e trabalho}

Provavelmente, a maioria das mulheres que escreve e frequenta a blogosfera materna, se questionada, diria que não há um recorte de classe ou raça nos blogs, que este é um espaço aberto a todas e que todos os debates são bem-vindos. Em minha tese de doutorado (PIRES, 2020), quando analisei o discurso proferido na blogosfera materna frequentada predominantemente por mulheres brancas, como nos portais de blogs Vila Mamífera e Minha Mãe que Disse, não identifiquei o reconhecimento de que a pauta ali desenvolvida dizia respeito a um grupo específico de mulheres. Em algumas passagens, há o reconhecimento de classe e de raça das participantes, mas não uma preocupação claramente delimitada deste recorte de público. Pelo contrário, são comuns as referências generalistas à maternidade e o cuidado materno como comportamentos inscritos em uma natureza feminina e que atingem uniformemente a todas as pessoas nascidas com o mesmo sexo biológico. São frequentes também as críticas àquelas que não seguem práticas consideradas importantes nos fóruns, como amamentar ou parir da forma mais natural possível, independentemente das condições socioeconômicas, raciais, culturais e se é ou não uma escolha da mulher ou da família.

4 O Iyá Maternância foi formado em 2016 e é composto por Luciana Bento, Xan Ravelli do Canal do youtube Soul Vaidosa, Priscila Silva do perfil do instablog Mãe nada convencional e Sá Ollibear do canal do youtube e blog Preta Pariu. Em agosto de 2020, a rede promoveu o I Congresso Online de Maternidades Negras. 
Temas como racismo e o preconceito sofrido pelas crianças negras, como apontam as blogueiras negras, são pouco ou nada abordados. Privilegiam-se debates em torno da gestação, em como realizar o parto, na relação mãe bebê, nos cuidados voltados à primeira infância (como amamentação, alimentação, educação, brinquedos, etc.) e na importância da criação de seres humanos melhores. Assuntos que poderiam ser considerados neutros porque comuns ao cotidiano da maioria das mães contemporâneas independentemente das condições socioeconômicas, raça ou do local de moradia delas. No entanto, a importância dada a determinados assuntos em detrimento de outros e a maneira como são tratados, sob o prisma de um grupo mais ou menos homogêneo de mulheres e que não incluem as especificidades das famílias pobres e as urgências da maternidade negra, evidenciam que não há neutralidade nestes fóruns. Debate-se, por exemplo, as vantagens do investimento em escolas privadas com métodos educacionais alternativos (e mensalidades caras) para as crianças enquanto boa parte da população sequer tem acesso à creche. É por isso que a análise do que é enunciado na blogosfera materna, para além da verificação do perfil de suas participantes, é elucidativa do viés de classe e raça que a atravessa, como denunciam as blogueiras negras a partir dos temas ausentes especificamente voltados à maternidade negra.

As disputas acerca dos feminismos e suas relações com a maternidade, a qual, a princípio, poderia se constituir como um destes temas neutros da blogosfera, quando analisado criteriosamente, reflete de qual lugar estão sendo enunciados e quais influências recebem. É comum que blogueiras e ativistas maternas se reivindiquem feministas. Tal postura é esperada, tendo em vista que estes discursos focam na possibilidade de escolha feminina, no empoderamento materno e na valorização da singularidade de gestar e parir: legados de teorias feministas e de movimentos de mulheres dos últimos cinquenta anos no Ocidente. Não há, porém, uma única vertente feminista seguida. Dividem espaço nos blogs, diferentes acepções de feminismo e diferentes concepções quanto à necessidade da permanência feminina no lar e quanto às possibilidades das mulheres engrossarem o mercado de trabalho formal. Encontramos mulheres que defendem enunciados relacionados às diferenças sexuais e à valorização das especificidades femininas, posição que poderia aproximálas de um feminismo diferencialista ${ }^{5}$, enquanto outras focam prioritariamente na garantia de direitos iguais entre homens e mulheres ${ }^{6}$. Há quem defenda um feminismo materno (BRUM, 2019, on-line) ou mamífero (PULHEZ, 2015) e um ativismo feminino proveniente dos feminismos, mas que deles se difere por ser

5 A filósofa francesa Elisabeth Badinter (2011) sugere que é esta visão diferencialista da maternidade que ainda ecoa nos movimentos ligados ao nascimento e constitui um dos tripés que sustentam a maternidade naturalista. As diferencialistas, como ficaram conhecidas feministas próximas a Luce Irigaray e Helène Cixous na França no início da década de 1980, eram assim denominadas em comparação com às seguidoras de Simone de Beauvoir, consideradas "igualitaristas" por reivindicarem uma identidade considerada comum a todas pessoas que possuíam o sexo feminino e que por isto seriam alvos da mesma forma de opressão masculina.

6 Autoras como Rosamaria Carneiro (2011) e Mariana Pulhez (2015), que desenvolveram pesquisas sobre a humanização do nascimento e a maternidade mamífera no Brasil respectivamente, defendem 
voltado à maternidade e ao cuidado infantil (RAMMI, 2013, on-line). Há também quem negue a filiação do ativismo maternalista aos feminismos por associá-los ao aumento das responsabilidades das mulheres e à geração de ambivalência entre elas.

A principal marca dos feminismos no discurso maternalista brasileiro é a possibilidade de escolha pela maternidade, herança das lutas feministas por direitos reprodutivos dos anos 1970 nos países ocidentais (HAYDEN; HALLSTEIN, 2010). É unânime, na blogosfera, a concepção de que as mulheres podem decidir ser mãe (o que não incluí necessariamente o direito ao aborto e sim a métodos contraceptivos), de que há modos distintos de ser mãe, como parir e maternar (ainda que sejam frequentes os julgamentos voltados àquelas que não parem ou maternam como considerado ideal pelo grupo, paradoxo que condiciona a escolha feminina). Não há, no entanto, a clareza da maior parte das blogueiras de que esta reivindicação tenha origem em movimentos feministas. Quando o tema é debatido, oportunidade em que algumas mulheres apontam o tom prescritivo da blogosfera, pouco se discute quais mulheres podem escolher a maternidade, em quais condições e quais são as opções reais de escolha que possuem.

É por compreender que a abordagem do direito reprodutivo é limitada por ser direcionada ao acesso à saúde e à escolha individual e por não abordar com profundidade as raízes das causas das disparidades no acesso e na efetivação destes direitos, que feministas, sobretudo mulheres negras, têm defendido o conceito de justiça reprodutiva ${ }^{7}$. O foco na escolha feminina, ao enfatizar a concepção neoliberal centrada no individuo, acaba por ocultar o contexto social em que os indivíduos as realizam e ignora as maneiras através das quais o Estado regula populações e exerce controle sobre a sexualidade, sexo e reprodução, além de limitar as reivindicações à esfera legal pelos direitos reprodutivos (NORONHA, 2016). A abordagem da Justiça Reprodutiva, por outro lado, reconhece as histórias de opressão e abuso nas comunidades, reconhece as intersecções de múltiplas opressões (raça, gênero, classe etc.) e usa como estratégia de mudança as organizações de meninas e mulheres para alterar a estrutura de poder (NORONHA, 2016).

A ênfase na escolha como direito individual feminino, sem que sejam problematizadas as condições sociais, econômicas, culturais e políticas para realizála, aproxima o discurso maternalista do universo on-line de uma retórica feminista restrita à defesa dos direitos femininos de ser mãe no âmbito individual alinhada ao mito de liberdade individual do liberalismo. A este respeito, a filósofa Angela Davis (2016, p. 210), afere que

(...) o slogan da "maternidade voluntária" continua uma visão nova e autenticamente progressista da condição da mulher. Ao mesmo tempo, entretanto, essa visão estava rigidamente associada ao estilo de vida de que gozavam a classe média e a burguesia. As

que estes discursos transitam entre as demandas diferencialistas e igualitaristas, coadunando "direitos de igualdade e de singularidade” ou especificidades femininas positivadas (CARNEIRO, 2011, p. 278).

7 Sobre o conceito de justiça reprodutiva, ver Kimala Price (2011) e Loretta Ross (2006). 
aspirações por trás da reivindicação da "maternidade voluntária" não refletiam as condições das mulheres da classe trabalhadora, engajadas em uma luta muito mais fundamental pela sobrevivência econômica. Uma vez que essa primeira reivindicação pelo controle de natalidade foi associada a objetivos que só poderiam ser atingidos por mulheres com riqueza material, um grande número de mulheres pobres e da classe trabalhadora tiveram certa dificuldade em se identificar com o embrionário movimento pelo controle de natalidade. ${ }^{8}$

Nas disputas relativas a quanto e como é uma mãe feminista na blogosfera materna, porém, a questão da escolha pela maternidade não aparece de forma central relacionada aos feminismos. Pouco são abordadas outras questões que poderiam ser consideradas demandas feministas como, por exemplo, a divisão do trabalho de cuidado entre o casal, os direitos reprodutivos como o aborto, entre outros. O que se encontra no cerne deste debate é a participação feminina no mercado de trabalho. O trabalho remunerado realizado fora de casa aparece constantemente relacionado aos feminismos, tanto em defesa da conciliação entre trabalho e maternidade como uma atitude feminista, quanto como uma imposição social que as feministas teriam ajudado a erigir e que é prejudicial às crianças, à família e à própria mulher. Nesta perspectiva, tal imposição que obriga as mulheres a trabalhar as faz assumir triplas jornadas de trabalho, o cuidado dos filhos, a carreira e ainda manterem-se atraentes e felizes.

As defesas feministas da segunda metade do século XX em torno do trabalho a outras trajetórias femininas possíveis, dentre as quais a recusa da maternidade como caminho para subverter a dominação masculina teriam, para algumas blogueiras, piorado a situação das mulheres que continuam a sofrer imposições a todo o momento. Para elas, "essa tal liberdade e direitos iguais só nos trouxe prejuízos e um fardo cada vez mais difícil de carregar!" (comentário apud MIRANDA, 2013, on-line). Esse fardo, imposto às mulheres a assunção de jornadas duplas e triplas de trabalho, já que agora a mulher "não pode trabalhar; ela tem que trabalhar" (MIRANDA, 2013, on-line), é o que leva algumas blogueiras a compreender que reafirmar o papel natural materno e privilegiar o cuidado dos filhos através de práticas voltadas ao que é considerado melhor para eles, significa resistir ao feminismo e não com ele pactuar. Argumentase frequentemente que há uma terceirização do cuidado, nociva às crianças, quando elas são deixadas com babás, familiares ou por períodos longos na escola. Há um chamamento para que as mulheres retornem ao lar integralmente, abandonando,

8 Kimala Price argumenta que muitas mulheres negras - assim como mulheres pobres, da classe trabalhadora e lésbicas - não se identificaram com o movimento "pró-escolha" por considerarem que negligenciava indicadores de diferença envolvidos nos direitos reprodutivos como raça, etnia, classe, sexualidade e falhava em ver como a reprodução está conectada a outras questões de justiça social, como justiça econômica, reforma do bem-estar, reforma penitenciária, sistemas de adoção e assistência social, imigração, direitos LGBT e questões ambientais (2011, p. 56). 
mesmo que temporariamente suas carreiras, ou empreendendo a fim de conciliar o emprego e a maternagem.

Há entre as blogueiras, portanto, uma identificação do trabalho remunerado feminino fora do lar como ponto cerne do feminismo. Praticamente todos os debates relativos ao movimento feminista que analisamos orbitam em torno do retorno ao lar, do trabalho fora dele ou da conciliação entre casa, cuidado infantil e trabalho remunerado. Mesmo nas postagens voltadas às defesas da luta feminista por direitos iguais ou à importância do feminismo mamífero, a possibilidade da mulher se dedicar exclusivamente à família ou trabalhar fora de casa aparece como central. As mães blogueiras brancas trazem ao debate, portanto, cada uma de acordo com suas convicções, a preocupação com o cuidado infantil após a saída de mulheres da casa para o mercado de trabalho. Elas buscam repensar quem faz o trabalho do cuidado enquanto a mãe trabalha e se vale a pena abrir mão da relação com os filhos em nome da carreira ou de empregos mal remunerados e insatisfatórios.

A importância que o trabalho fora de casa recebe entre as mães em relação aos seus filhos, como em um conflito entre uma autonomia feminina e a qualidade do cuidado infantil, reflete as contradições da maternidade contemporânea diagnosticadas pela socióloga Sharon Hays na década de 1990. Em sua pesquisa, realizada com mulheres estadunidenses majoritariamente brancas de diferentes classes sociais ${ }^{9}$, Hays identificou a ascensão de práticas de maternagem baseadas no cuidado intensivo das mães para com os filhos e filhas, estejam elas ou não no mercado de trabalho formal, em um constante conflito entre a maternagem centrada na criança e a valorização da carreira profissional. Segundo ela, tanto as mães que se dedicam também a uma carreira quanto às que se dedicam integralmente à família expressam ambivalência sobre suas escolhas, ainda que as justifiquem, sentimentos de culpa e de inadequação. Ambas, porém, mantêm a lógica da maternidade intensificada em que as necessidades dos filhos devem estar acima das necessidades das mulheres. Esses papéis desconfortáveis esperados e atribuídos às mães compõem a contradição cultural contemporânea em que as mulheres se encontram, segundo a autora.

Assim como a maioria das mulheres que escrevem nos blogs maternos por mim analisados, as entrevistadas por Hays são em sua maioria brancas. Nos dois contextos, é possível identificar a defesa de uma maternidade realizada de forma intensiva em meio ao dilema de manter ou não a carreira profissional após o nascimento dos filhos, debate que na blogosfera é atravessado pela disputa de feminismos e antifeminismos. O diagnóstico de Hays feitos nos Estados Unidos na década de 1990, que aparece também na blogosfera brasileira guardadas suas especificidades, demonstra como a possibilidade das mulheres brancas de classes não trabalhadoras de exercer trabalho remunerado não as libertou da posição de principal cuidadora dos filhos e alicerce

9 Segundo a autora, das trinta e oito entrevistadas seis eram latino-americanas, duas afro-americanas, duas asiático-americanas, uma ítalo-americana e as demais eram todas brancas. (HAYS, 1998, p. XII) Interessante notar que ela não inclui mulheres de ascendência italiana entre as brancas, como faríamos aqui no Brasil. 
familiar e de como esta condição se apresenta comumente enquanto efeito das demandas feministas por igualdade e possibilidade de escolha. Transitando entre enunciados feministas de diversas vertentes e antifeministas, apesar dos apelos à autonomia feminina, a maternidade e o cuidado infantil e familiar permanecem como essência do cumprimento do papel feminino, ainda que as mulheres possam dedicar-se à uma carreira profissional ${ }^{10}$.

Se Hays não situa esta contradição contemporânea entre as mulheres brancas, outra autora, a feminista negra estadounidense bell hooks ${ }^{11}$, ao trazer para o debate as experiências de maternidade e maternagem de mulheres negras, nos ajuda a compreendê-la enquanto prática discursiva situada entre as mulheres-mães brancas, de classes médias e altas, tributárias de movimentos feministas também brancos que contribuem para a romantização do papel social da mãe. hooks aborda esta temática em seu livro Teoria feminista: da margem ao centro, o qual nos centramos a seguir.

Escrito na década de $1980^{12}$, Teoria Feminista da margem ao centro teve como motivação a ausência de uma teoria feminista que abrangesse diferentes perspectivas sobre ser mulher, segundo a autora. As teorias hegemônicas à época eram escritas por mulheres privilegiadas, em sua maioria brancas, com ensino superior e de classes médias. Suas proposições pouco ou nada traziam da perspectiva das mulheres que estavam nas margens sociais, nas extremidades, como as mulheres negras e as mulheres brancas pobres, como as moradoras das periferias que frequentam o centro da cidade para trabalhar, mas não podem nele residir. Ao deixar de fora outras possibilidades de ser mulher, estas teorias traziam visões empobrecidas das relações sociais, do sexismo e do racismo. Faltava-lhes amplitude analítica e inteireza. Como resposta a esta situação, a autora propõe a criação de uma teoria feminista capaz de mapear ideias e estratégias para um movimento de massas, de uma teoria que falasse a todos e todas e que fosse enraizada em questões de raça, classe e gênero. Tratavase, para ela, de criar uma abordagem que se propusesse a pensar tanto as margens quanto o centro, de forma enriquecedora, evidenciando que não há uma mulher ou um feminismo que sirva a todas. (hooks, 2019, p. 23)

De acordo com hooks, as análises feministas que se organizaram em torno da libertação feminina e do entendimento da maternidade como principal razão da opressão das mulheres, refletiam o viés de raça e classe das participantes. Exemplo disto, é a publicação da A Mística Feminina em 1963 por Betty Friedan, livro apontado como precursor do movimento feminista nos Estados Unidos. A condição da mulher, descrita na obra, se refere ao drama de um seleto grupo de mulheres brancas de classe média e alta, com ensino superior. O "problema que não tem nome”, proposto

10 A esse propósito, o neurocientista Davi Thornton (2014) identifica um entrelaçamento entre feminismo e antifeminismo na retórica da maternidade contemporânea, que integra ideais e discursos feministas ao neoliberalismo. Fenômeno que Susan Douglas e Meredith Michaels (2004) também identificam na visão romantizada da maternidade atual, o new momism, que tanto inspira quanto repudia os feminismos, distorcendo-os.

11 Pseudônimo de Gloria Jean Watkins. A autora prefere que seja escrito em letra minúscula para dar mais enfoque à sua escrita do que a sua pessoa.

12 A obra só foi traduzida e publicada no Brasil em 2019. 
por Friedan, nomeava a insatisfação destas mulheres que, entediadas pelo trabalho doméstico, pelo cuidado das crianças e pelas horas de lazer, esperavam mais da vida e queriam uma carreira profissional. A maternidade, neste sentido, constituía-se como um obstáculo à libertação feminina ao confiná-las em casa mantendo-as prisioneiras do trabalho doméstico e do cuidado dos filhos. Trabalhar fora de casa era entendido como a condição que propiciaria às mulheres deixarem de ser economicamente dependentes dos homens, e consequentemente da dominação sexista.

hooks chama atenção para como estas defesas estavam tão mergulhadas em suas próprias experiências que ignoravam que a maioria das mulheres já trabalhava fora de casa em trabalhos mal remunerados e que não as libertavam da dependência masculina. Elas ignoravam a existência de outras mulheres não brancas e de trabalhadoras pobres. A busca por libertação pelo trabalho referia-se a carreiras bem remuneradas que exigiam formação acadêmica ou a manutenção dos padrões de vida de classe média que não podiam ser sustentados apenas com a renda dos maridos. Ao fazê-lo, sem reconhecer quais posições ocupavam, feministas como Friedan acabaram por transformar o drama de um grupo de mulheres em sinônimo da condição de todas as mulheres nos Estados Unidos, pondera hooks. Esta perspectiva unidimensional do ser mulher teria se tornado um traço marcante do movimento feminista, disfarçando atitudes classistas, racistas e sexistas em relação ao conjunto da população feminina.

Para hooks, este discurso afastava trabalhadoras e mulheres negras do feminismo, as quais, segundo a lógica da libertação via trabalho remunerado, já estariam "libertas". Era como se dissessem a estas mulheres que o feminismo não era pra elas, que o movimento servia aos interesses de uma classe. Para as mulheres negras não havia identificação possível com feminismos que viam o mundo do trabalho como libertador. Como pondera a autora, a maternidade para as mães negras nunca se constituiu um obstáculo grave à liberdade feminina ou à entrada no mundo do trabalho remunerado. Desde a escravidão, tanto nos Estados Unidos quanto no Brasil'13, as mulheres negras sempre trabalharam em atividades no campo, nas fábricas, nas casas alheias, em trabalhos mal remunerados.

Historicamente, as mulheres negras têm visto o trabalho no contexto familiar como um labor que humaniza, que afirma a sua identidade como mulheres, como seres humanos que

13 Quanto à realidade brasileira, a filósofa Sueli Carneiro (2019. p. 314), afere que "as mulheres negras tiveram uma experiência histórica diferenciada que o discurso clássico sobre a opressão da mulher não tem reconhecido, assim como não têm dado conta da diferença qualitativa que o efeito da opressão sofrida teve e ainda tem na identidade feminina das mulheres negras. Quando falamos do mito da fragilidade feminina, que justificou historicamente a proteção paternalista dos homens sobre as mulheres, de que mulheres estamos falando? Nós, mulheres negras, fazemos parte de um contingente de mulheres, provavelmente majoritário, que nunca reconheceram em si mesmas esse mito, porque nunca fomos tratadas como frágeis. Fazemos parte de um contingente de mulheres que trabalharam durante séculos como escravas nas lavouras ou nas ruas, como vendedoras, quituteiras, prostitutas... Mulheres que não entenderam nada quando as feministas disseram que as mulheres deveriam ganhar as ruas e trabalhar!". 
demonstram amor e carinho, justamente os gestos de humanidade que a ideologia supremacista branca havia acusado os negros de serem incapazes de expressar. Em contraste com o trabalho feito dentro de casa, num ambiente de cuidados, o trabalho fora de casa geralmente era visto como estressante, degradante e desumanizador. (hooks, 2019, p. 195-196)

Diferentemente das ativistas brancas de classe média que edificaram feminismos pautados na crença de que exercer trabalho remunerado gera libertação, as mulheres pobres e as mulheres negras já percebiam o mundo do trabalho fora de casa como alienado e queriam dele sair, queriam ter mais tempo para suas famílias. Elas sabiam por experiência própria que o trabalho não as libertava, e sim as explorava e desumanizava-as. Enquanto isto, as mulheres brancas de classes abastadas não conheciam e não consideravam os problemas do mundo do trabalho, o entendiam apenas da perspectiva da realização pessoal, analisa hooks. Porém, ao entrarem para a vida ativa remunerada a partir dos anos 1960, as mulheres brancas:

descobriram que trabalhar num contexto social em que o sexismo ainda é a norma, em que inveja, desconfiança, antagonismo e malícia contaminam as relações no trabalho por conta da excessiva competição entre as pessoas, que tudo isso torna o trabalho estressante e frustrante e não raro fonte de completa insatisfação. Já as mulheres que se sentem mais felizes com seus empregos acabam se ressentindo da falta de tempo para buscar outras formas de satisfação na vida. Se o trabalho pode ajudar as mulheres a adquirir algum um grau de independência financeira ou mesmo de total autossuficiência, para a maioria das mulheres, ele não atende adequadamente às suas necessidades de realização como seres humanos. (hooks, 2019, p. 104-105)

Para hooks, perceber como é insatisfatório e frustrante o mundo do trabalho levou-as a repensar a importância da família e dos aspectos positivos da maternidade. Em busca de um trabalho gratificante realizado em um ambiente afetivo e de uma tentativa de reparação pelos danos causados pelas críticas feministas do passado, esse movimento teria se desdobrado em uma atenção feminista em respeito às mulheres que se tornam mães, a qual positiva a maternidade baseada em estereótipos sexistas. Segundo a autora, "ao romantizar a maternidade, ao empregar a mesma terminologia sexista usada para sugerir que as mulheres são nutrizes naturais a favor da vida, as ativistas feministas reforçam os principais pilares da ideologia supremacista masculina" (p. 198) ${ }^{14}$. De acordo com ela, esta positivação da maternidade é tão romantizada por algumas ativistas feministas como era pelos homens brancos e

$14 \mathrm{O}$ ressurgimento do interesse pela maternidade tem como implicação positiva para hooks (2018) a existência da representatividade materna nos movimentos feministas e a necessidade contínua de estudos e pesquisas sobre a parentalidade feminina. 
pelas mulheres brancas do século XIX, que louvavam as "virtudes domésticas" das mães brancas ${ }^{15}$, ainda que, recentemente, a romantização esteja mais focada nas alegrias da maternidade, na intimidade especial, na proximidade e na ligação íntima que supostamente caracteriza a relação mãe/filho. Sugere-se, nos dias atuais, que as mulheres são inerentemente educadoras a favor da vida; que a maternidade é a verdadeira vocação da mulher; que as mulheres que não são mães, cujas vidas se concentram mais exclusivamente na carreira, no trabalho criativo ou político, estão condenadas a viver vidas insatisfatórias a nível emocional; que ter filhos é mais importante e mais gratificante do que qualquer outro trabalho que as mulheres possam ter.

hooks afirma que mesmo as teóricas feministas que salientam a necessidade dos homens participarem igualmente na educação das crianças são reticentes em deixar de dar um valor especial à maternidade, glorificando a experiência fisiológica. Sara Ruddick, em seu ensaio Maternal Thinking (1982) ${ }^{16}$, é uma das feministas que, de acordo com a autora, romantiza a ideia de "materno" e destaca a transformação dos homens em figuras maternais ${ }^{17}$ de forma redutora. Neste ensaio, Ruddick defende que os homens devem dividir o cuidado dos filhos e viver num pensamento maternal tornando-se "mães" de ambos os sexos (hooks, 2019). hooks pondera que uma vez que a palavra materno é associada ao comportamento das mulheres, além dos homens não se identificarem com ela, esta concepção reforça a ideia estereotipada sexista de que as mulheres são inerentemente mais aptas para educar do que os homens, de que o cuidado infantil é uma vocação, e de que os homens que educam da mesma forma que as mulheres estão imitando-as, feminizando-se, em vez de agir como pais. A experiência biológica da gravidez e do parto, não deveria ser usada, em sua visão, para afirmar a parentalidade feminina como superior à exercida pelos homens. Isto porque, enquanto a relação mãe e filho for enxergada como única e especial devido à geração e parturição, a responsabilidade pela criação e pelo cuidado parental continuará sendo primordialmente feminina. A autora aponta ainda que o cuidado maternal intensivo, como o defendido por Ruddick, é uma forma de cuidado voltada às classes burguesas compostas por famílias nucleares e com estrutura (econômica, inclusive) que as permita fazê-lo. É difícil para trabalhadores e trabalhadoras chegarem em casa após um dia de trabalho e darem atenção

15 A idealização da maternidade não se aplicava nesta época às mulheres negras. A este respeito, Angela Davis lembra que "a exaltação ideológica da maternidade - tão popular no século XIX - não se estendia às escravas. Na verdade, aos olhos de seus proprietários, elas não eram realmente mães; eram apenas instrumentos que garantiam a ampliação da força de trabalho escrava. Elas eram "reprodutoras" - animais cujo valor monetário podia ser calculado com precisão a partir de sua capacidade de se multiplicar" (DAVIS, 2016, p. 25-26).

16 O livro de Ruddick de mesmo título Mathernal Thinking: Toward a Politics of Peace foi publicado anos depois em 1989.

17 A ideia de enaltecer o feminino a ponto de "feminizar" os homens, também encontra-se presente nos discursos presentes na blogosfera materna brasileira, como refere Mariana Pulhez (2015) em sua pesquisa sobre o blog Mamíferas. 
especial à parentalidade, sobretudo quando as mulheres são as únicas cuidadoras das crianças. Além de suas consequências às mães, a autora preocupa-se com as consequências às crianças, por considerar que a centralização do cuidado tende a um excesso de investimento emocional de mães e pais em relação à prole.

Para hooks, o perigo desta romantização da maternidade para o movimento feminista e para as mulheres, com seu forte componente de raça e classe, é dizer que as mulheres estão destruindo a vida familiar ao não assumirem os papéis determinados pelo sexismo; éfazê-las continuar a assumir a responsabilidade exclusiva pela educação dos filhos, é levá-las à pobreza (considerando que as mulheres que têm filhos têm mais probabilidades de viver entre a população pobre). É por este motivo que hooks propõe, a partir da experiência de pessoas criadas em comunidades negras, uma nova parentalidade baseada na comunidade, em que há partilha de responsabilidade pela educação das crianças ${ }^{18}{ }^{19}$. Para a autora, o movimento feminista deve lutar pela reestruturação da sociedade para que as mulheres não sejam as únicas a prestar esse cuidado, para que a maternidade não seja uma experiência obrigatória, nem exploradora, nem opressiva a nós.

O olhar da margem de bell hooks (2019, p. 23) para os feminismos brancos, "tanto de fora pra dentro, quanto de dentro pra fora", permite perceber quanto tanto os feminismos que identificam na maternidade o lócus da opressão e o trabalho como libertação, quanto aqueles que a valorizam enquanto atributo feminino são localizados, possuem recorte de classe e raça e não abrangem diversas possibilidades e experiências de ser mãe e de ser mulher. Evidentemente outras feministas negras também contribuem para evidenciar os limites dos feminismos brancos e as especificidades da maternidade e maternagem negras - como Patricia Hill Collins, Angela Davis e Sueli Carneiro - mas hooks é particularmente importante na discussão que proponho, por identificar uma romantização da maternidade como consequência da ilusão feminina branca de que o trabalho poderia propiciar a libertação da dominação masculina. Ainda que a autora debata o contexto estadunidense, esta romantização é passível de ser identificada na blogosfera materna branca brasileira, assim como a presença na composição deste discurso de teorias feministas brancas e de comportamentos de mulheres-mães estadunidenses que ressoam em nossos modelos ideais de maternidade.

18 Uma possibilidade sugerida pela autora para tal reestruturação é a criação de centros infantis públicos que empreguem igual número de trabalhadores homens e mulheres. Esses centros, ela esclarece, têm como objetivo assegurar ajuda comunitária como suplemento das obrigações próprias dos pais e das mães.

19 Patricia Hill Collins (1990) também chama a atenção para a partilha do cuidado infantil das mães biológica com outras mulheres, pessoas da família e vizinhos nas comunidades negras em que o modelo de família nuclear é exceção. A autora, assim como hooks, defende que a responsabilização total de uma pessoa pelo cuidado infantil, como se o filho fosse propriedade privada dos geradores, não é possível e saudável. Para ela, as crianças deveriam ser vistas como membros valiosas da comunidade que precisam de uma ampla rede de apoio. Nesta perspectiva, ativistas, outras mães (othermothers) e educadores podem contribuir para uma outra forma maternagem (othermothering), para o cuidado e bem-estar das crianças (COLLINS, 1990). 


\section{A narrativa universalizante do discurso maternalista nacional}

Neste artigo, procurei evidenciar o recorte de classe e raça da blogosfera materna através tanto da análise do discurso proferido acerca dos feminismos quanto a partir da própria identificação de blogueiras negras de quão circunscrito é este espaço. Os debates travados em torno dos feminismos reforçam o perfil e o lugar de onde falam essas mulheres que escrevem e comentam nas mídias sociais. São as mulheres intelectualizadas, brancas e de classes médias ou altas, as que podem individualmente escolher entre retornar ao lar ou realizar trabalhos remunerados em casa, em razão de suas condições financeiras e das profissões exercidas. Para muitas mulheres brancas das classes populares e para a maioria das mulheres negras, trabalhar fora ou fazer "bicos" para sustentar a família e cuidar da casa e dos filhos, sempre foi a única opção. Estas estão, muitas vezes, trabalhando na casa de outras mulheres, cuidando de suas casas e de suas crianças. Como argumenta bell hooks (2019), a preocupação do feminismo branco da virada do século XIX e $\mathrm{XX}$ que associa maternidade à opressão sempre foi racializada; as mulheres negras e pobres já conheciam as dificuldades que o trabalho gerava e sabiam que a dominação masculina não depende apenas do exercício de atividades remuneradas.

O discurso maternalista da blogosfera, que possui em sua composição teorias feministas elaboradas por mulheres brancas sobre sua realidade, acaba por universalizar um modelo de maternidade a partir da perspectiva branca, generalizando o que é ser mulher e o que é mãe. A seu favor, o discurso conta com argumentação científica que define a maternidade e a maternagem a partir de uma natureza feminina, de condições fisiológicas daquelas que nasceram com o mesmo sexo biológico e de pressupostos quanto a relação mãe e bebê homogeinizadores. A maternidade e a maternagem retratadas na blogosfera materna brasileira, assim, pouco abrangem outras formas de ser mãe e de maternar. O cuidado infantil compartilhado com outras mulheres, familiares e vizinhos em comunidades negras, como nos mostra bell hooks e Patricia Hill Collins, faz com que a maternidade negra não seja entendida sob o signo da opressão, como o é para muitas mulheres brancas. Pelo contrário, a maternidade pode ser valorizada nestas comunidades e se constituir como forma de politização feminina e levar as mães à ação política (COLLINS, 1990).

O debate acerca de temas cotidianos da maternidade e voltados para opressão de gênero tampouco dá conta da complexidade das questões que afligem as mães negras, que tem que lidar com diversas opressões como as de classe e de raça. Desde a escravização, estas mulheres lutam constantemente para proteger seus filhos e filhas de situações de vulnerabilidade, como de violências cometidas contra jovens negros e negras e o encarceramento desta população, tanto nos Estados Unidos quanto no Brasil (COLLINS, 1990; DAVIS, 2019). O distanciamento do debate na blogosfera materna brasileira branca do universo e das questões das mães negras é evidenciado por mulheres negras que criam blogs, grupos de apoio e projetos de leitura voltados às suas próprias realidades. Advogando um debate maternalista voltado para as 
questões raciais em contraposição à ausência declarada de cor e de raça dos demais blogs, as blogueiras negras demarcam o quanto sob a aparência de neutralidade a blogosfera materna é branca. A suposta "invisibilidade" branca dos blogs maternos é assim visibilizada pelas mães ativistas negras, fazendo que a condição de branco e de classe seja exposta, demonstrando como este discurso ajuda a manter, em um pacto narcísico da branquitude (BENTO, 2002), sob seu controle, a maternidade branca como modelar.

\section{Referências}

AGUIAR, Ione. A brutal diferença entre um parto no SUS e um parto humanizado em hospital particular. Justiça de Saia. 22 mar. 2017. Disponível em: <http://www. justicadesaia.com.br/a-brutal-diferenca-entre-um-parto-no-sus-e-um-partohumanizado-em-hospital-particular/>. Acesso em: 17 abr. 2018.

ASSUNÇÃO, Mayara. A blogosfera materna se silenciou. Geledés. 23 nov. 2017. Disponível em: <https://www.geledes.org.br/blogosfera-materna-se-silenciou/>. Acesso em: 18 fev. 2020.

BADINTER, Elisabeth. O conflito: a mulher e a mãe. Rio de Janeiro: Record, 2011.

BENTO, Maria Aparecida. Pactos narcísicos no racismo: Branquitude e poder nas organizações empresariais e no poder público. Tese (Doutorado em Psicologia). São Paulo: Universidade de São Paulo, 2002.

BLOGUEIRAS NEGRAS. \#25WebNegras: Juntas somos mais. Blogueiras Negras. 29. dez. 2017. Disponível em: <http://blogueirasnegras.org/25webnegras-juntas-somosmais/>. Acesso em 15. fev. 2021.

CARNEIRO, Rosamaria. Cenas de parto e políticas do corpo: uma etnografia de experiências femininas de parto humanizado. Tese (Doutorado em Antropologia). Campinas: Universidade Estadual de Campinas, 2011.

CARNEIRO, Sueli. Enegrecer o feminismo: a situação negra na América latina a partir de uma perspectiva de gênero. In: HOLLANDA, H (org.). Pensamento feminista: conceitos fundamentais. Rio de Janeiro: Bazar do Tempo, 2019, p. 313-321.

CAVALLIERI, Carla. Iniciação.... Nana Maternidade Negra. 22 abr. 2017. Disponível em: <https://nanamaternidadepreta.wordpress.com/page/2/>. Acesso em 15 fev. 2021. 
CAVALLIERI, Carla. Percalços de uma maternidade dividida em cores. Nana Maternidade Negra. 26 abr. 2018. Disponível em: <https://nanamaternidadepreta. wordpress.com/page/2/>. Acesso em: 15 fev. 2021.

COLLINS, Patricia Hill. Black Feminist Thought: Knowledge, Consciousness and the Politics of Empowerment. New York: Routledge, 2008.

DAVIS, Angela. Mulheres, raça e classe. São Paulo: Boitempo, 2016.

DOUGLAS, Susan J.; MICHAELS, Meredith W. The mommy myth: The idealization of motherhood and how it has undermined all women. New York: Free Press. 2004.

HAYDEN, Sara; HALLSTEIN, Lynn O'Brien. Contemplating maternity in an era of choice. Lanham, MD: Lexington Books, 2010.

HAYS, Sharon. Contradições culturais da maternidade. Rio de Janeiro: Gryphus, 1998.

HOOKS, Bell. Teoria Feminista: da margem ao centro. São Paulo: Perspectiva, 2019.

JORNAL ROSA CHOQUE. Mãe cria blog sobre maternidade e racismo após vivências da gestação. Geledés. 17 set. 2018. Disponível em: <https://www.geledes.org.br/maecria-blog-sobre-maternidade-e-racismo-apos-vivencias-da-gestacao/>. Acesso em: 15 fev. 2021.

LEAL, Maria do Carmo et al. A cor da dor: iniquidades raciais na atenção pré-natal e ao parto no Brasil. Cadernos de Saúde Pública, Rio de Janeiro, vol. 33, supl. 1, eooo78816, 2017.

MIRANDA, Lia. Na fogueira dos sutiãs, ficaram muitos corações. Minha Mãe que Disse. 25 abr. 2013. Disponível em: <http://minhamaequedisse.com/na-fogueira-dossutias-ficaram-muitos-coracoes/>. Acesso em: 23 out. 2019.

MIRANDA, Karoline. Relato de Parto. Uma mãe feminista. 25 jul. 2016. Disponível em: <https://umamaefeminista.blogspot.com/2016/o7/relato-de-parto.html>. Acesso em: 18 fev. 2020.

NORONHA, Rayane. Por que a Justiça Reprodutiva é relevante para a luta pelo fim da violência contra as mulheres? Portal Catarinas. 30 nov. 2016. Disponível em:<https:// catarinas.info/justica-reprodutiva-e-relevante-para-a-luta-pelo-fim-da-violenciacontra-as-mulheres/>. Acesso em: 17 mar. 2020.

PIRES, Elaine Muniz. Maternidade ativa e cuidado do mundo. Tese (Doutorado em Educação). São Paulo: Universidade de São Paulo, 2020. 
PRICE, Kimala. It 's not just about abortion: incorporating intersectionality in research about women of colour and reproduction. In: Women's Health Issues, [S.L.], v. 21, n. 3, p. 55-57, maio 2011. Disponível em: <https://www.whijournal.com/article/S10493867(11)ooo15-6/fulltext>. Acesso em: 17 mar. 2020.

PULHEZ, Mariana Marques. Mulheres mamíferas: práticas da maternidade ativa. Dissertação (Mestrado em Antropologia). Campinas: Universidade Estadual de Campinas, 2015.

RAMMI, Anne. Manifesto Maternista. Minha Mãe que Disse. 17 mar. 2013. Disponível em: <http://minhamaequedisse.com/manifesto-maternista/>. Acesso em: 23 out. 2019 .

ROSS, Loreta. What is reproductive justice? In: Sistersong Women of Color Reproductive Health Collective \& Pro-Choice Public Education Project. Reproductive justice briefing book: a primer on reproductive justice and social change, p. 4-5, 2007.

SILVA, Juliana Pereira Souza. Para mães negras ativistas, desenvolver a negritude nas crianças é questão de sobrevivência. 17 mai. 2018. Brasilidade Negra. Disponível em: $<$ https://brasilidadenegra.com/2018/05/17/para-maes-negras-ativistas-desenvolvera-negritude-nas-criancas-e-questao-de-sobrevivencia/>. Acesso em: 15 fev. 2021.

SILVA, Priscilla. Caso O Que Você Precisa Não Exista, Então O Terá Que Fazer! 2017. Movimento Black Money. Disponível em: <https://movimentoblackmoney.com.br/ caso-o-que-voce-precisa-nao-exista-entao-voce-o-tera-que-fazer/>. Acesso em: 15 fev. 2021.

THORNTON, David. Transformations of the Ideal Mother: The Story of Mommy Economicus and Her Amazing Brain. In: Women's Studies in Communication, [S.L.], v. 37, p. 271-291, 2 set. 2014 .

VIANA, Victor; MIRANDA, Karoline. mãe solo e feminista, fala sobre os cuidados na educação de uma criança negra. 05 nov. 2019. Purebreak. Disponível em: <https:// www.purebreak.com.br/noticias/consciencia-negra-karoline-miranda-mae-solo-efeminista-fala-sobre-como-criar-uma-crianca-negra/90967>. Acesso em: 15 fev. 2021.

Recebido em 20/03/2021.

Aceito em 01/06/2021. 